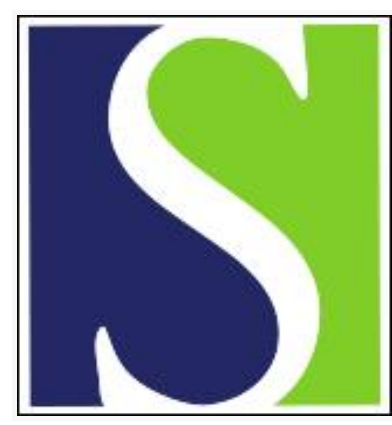

Scand J Work Environ Health 1976;2(1):73-89

https://doi.org/10.5271/sjweh.2829

Issue date: 1976

\title{
A mortality study of foundry workers.
}

by Koskela R-S, Hernberg S, Kärävä R, Järvinen E, Nurminen M

The following article refers to this text: 1989;15(4):245-264

Key terms: coronary heart disease; foundry worker; lung cancer; mortality; mortality study; retrospective cohort sutdy; violent death

This article in PubMed: www.ncbi.nlm.nih.gov/pubmed/968468

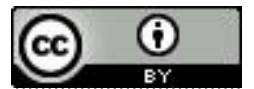




\title{
A mortality study of foundry workers
}

\author{
by RIITTA-SISKO KOSKELA, M.Sc., SVEN HERNBERG, M.D., \\ RISTO KÄRÄVÄ, M.D., ERKKI JÄRVINEN, M.Sc., and \\ MARKKU NURMINEN, Lic. Sc. ${ }^{1}$
}

\begin{abstract}
KOSKELA, R.-S., HERNBERG, S., KÄRÄVÄ, R., JÄRVINEN, E. and NURMINEN, M. A mortality study of foundry workers. Scand. $j$. work environ. \& health 2 (1976): suppl. 1, 73-89. The mortality of foundry workers was studied from a sample of all those men employed in 20 representative iron, steel, and nonferrous foundries for any period of time during 1950 through 1972. A statistical sample of 3,876 men from all those 15,401 workers with at least 3 months' exposure formed the cohort under study. The actual number of person-years of follow-up became 47,160. Total and cause-specific mortality was studied in the entire cohort and in different categories based on exposure time and occupation. The foundry workers' experience was compared to that expected on the basis of the general male population's death rates in Finland, and different categories of the cohort were compared to each other through direct standardization. During the period from 1950 through 1973, there had occurred 224 deaths. The mortality approached the expected value computed from the age-adjusted general male population, the standardized mortality ratio (SMR) being 90 for all foundry workers and $\mathbf{9 5}$ for workers in "typical" foundry occupations. The corresponding standard mortality ratios based on the estimated total number of person-years, after the application of corrections for sampling fractions, were 86 and 95, respectively. There was a slight shift of the age of death towards younger age groups among the casters, fettlers, and furnace tenders. Mortality from coronary heart disease showed a standardized mortality ratio of 80 for the whole cohort; no significant differences were found for any occupational category. Lung cancer mortality was higher than expected (SMR 150) in the entire cohort; closer analysis revealed that the excess was confined to iron foundries, and especially to molders with more than 5 years of exposure. There were no more violent deaths than expected, not even from work accidents. Because most occupational cohorts have standardized mortality ratios that are well below 90 , the present results were interpreted as probably indicating slightly elevated mortality. The most important finding was the concentration of lung cancer among molders in iron foundries.
\end{abstract}

Key words: foundry workers, mortality, retrospective cohort study, coronary heart disease, lung cancer, violent deaths.

The work environment in a foundry is characterized by a multitude of concomitantly occurring exposures, such as silica dust, various chemicals - among them carbon monoxide - noise, heat radiation, etc., as well as strenuous physical work

\footnotetext{
1 Department of Epidemiology and Biometry, Institute of Occupational Health, Helsinki, Finland.
}

Reprint requests to: Ms. Riitta-Sisko Koskela, Institute of Occupational Health, Haartmaninkatu 1, FIN-00290 Helsinki 29, Finland. and poor work positions. Although the health effects of many of these exposures are well known when they act alone, possible nonspecific health effects, caused by the interaction of the multiple stress factors and perhaps manifested as a change in the "normal" morbidity and mortality pattern, have not received much attention. Furthermore, many of the chemicals present in the air, among them various products of pyrolysis, may have hitherto unrecognized effects. In order to shed some 


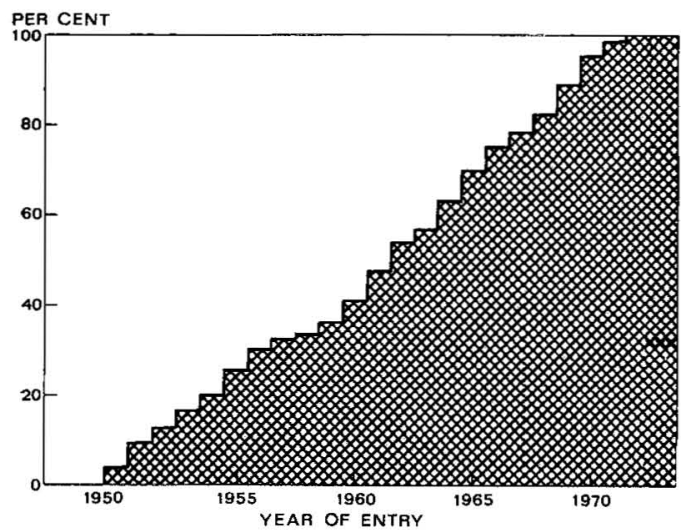

Fig. 1. Annual cohort (sample) entries expressed as the cumulative percentage.

light on these questions, we decided to examine the mortality of a sample of active and retired foundry workers.

\section{MATERIAL AND METHODS}

The population under study was formed from the 15,401 men employed for some period between 1 January 1950 and 31 December 1972 in the 20 foundries selected for the epidemiologic part of the Finnish Foundry Project (6). Hence both former and present workers were included. All the 1,233 men who had been employed during any period for at least 5 years were included in the cohort. Because of the high rate of turnover, which was anticipated prior to the study and actually proven by it (10), we also included a sample of foundry workers with a working history of less than 5 years in foundries. This sample comprised all men exposed for 3 to 5 years $(\mathrm{N}=629)$, every second of those exposed for 1 to 3 years $(N=1,042)$, and every tenth of those exposed for 3 months to 1 year $(\mathrm{N}=972)$. The total size of the cohort thus became 3,876 men. All deaths occurring before 31 December 1973 were included. The annual entry into the cohort can be seen from fig. 1, which shows that no major fluctuations occurred in the sample (10). Since different sampling coefficients were used for different exposure categories, an estimation of the personyears at risk was also made which allowed for the different coefficients. This estimation increased the weight of the categories with shorter exposure times, and the estimated total number of person-years at risk thus became 176,468 .

The basic information was collected from the employers' records by two of our technicians. The information included a complete history of foundry work beginning from the first employment at the foundry in question from 1950 through 1972 , as well as information relevant for the follow-up and tracing of subjects.

Those 3,876 men chosen for the mortality study were traced through the Population Data Register of the Social Insurance Institution. The register includes the entire Finnish population alive at the beginning of 1967 and from then on, in addition, all deceased persons. Those who could not be identified from the register were traced from church registry offices on the basis of the last place of residence and/or the native parish. In all, follow-up was successful for $98.7 \%$ of the cohort. The proportion of persons who were lost is shown in table 1.

The missing information from less than $2 \%$ of the cohort cannot have much effect on the mortality figures. In the calculation of the results, all missing persons were assumed to be alive. Most of them were young and had worked in a foundry for less than 1 year.

The causes of death were verified from the death certificates according to the eighth revision of the international classification of diseases (18). In addition more detailed information was obtained from the Finnish Cancer Registry whenever cancer was noted as the primary cause of death.

\section{Exposure data}

The exposure times were obtained from the data recorded in the employers' records. They present an obvious underestimate because only the time spent in that specific foundry could be recorded. These errors are discussed in detail elsewhere (10). The error was the smallest for the workers still employed in the foundries and for those with a long working history at the same foundry.

For the lung cancer cases the difference between the recorded and actual exposure 
time was evaluated from questionnaires sent to relatives. This procedure revealed that the error was greater for dead than for living persons, especially in the older age groups, because some of them had entered the cohort before 1950. Hence the optimal procedure would have been to verify the exposure time of every member of the cohort by means of a questionnaire, but this practice is unfeasible for large cohorts. Furthermore, those who had been exposed before 1950 should have been excluded irrespective of whether they were alive or dead. This would probably have produced slightly lower mortality figures; for the reasons already mentioned, the number of deaths would have been reduced relatively more than the number of personyears.

The duration of exposure was classified on the basis of the classification used in forming the sample ( 3 months-1 year, $1.0-2.9$ years, $3.0-4.9$ years, $>5.0$ years). Moreover, in the cause-specific mortality analysis, the 5 years or more exposure category was divided into subcategories of 5.0 to $9.9,10$ to 14.9 , and over 15 years of exposure time. We also formed different minimum exposure categories in order to decrease the effect of misclassifications of the exposure time; however the results with such a system were essentially the same.

The type of exposure was classified according to (a) the type of foundry (iron, steel and nonferrous), (b) category of carbon monoxide exposure (7), and (c) category of dust exposure (8). These classifications are, of course, crude because of differences in the precision and uniformity of the occupational labels. Furthermore, one person may have done more than one job during his foundry history.

\section{Basis for comparisons}

Since it seemed extremely difficult to find other occupational groups providing meaningful reference, no external comparison group was formed. Foundry work is strenuous and demanding and it exposes the worker to a number of physical and chemical hazards. The study of the effects of each of these hazards would have required a comparison group similar in all other respects but the hazard in question, and such groups are not readily available. On the other hand a reference group with no special exposures and light work might have given an overly unfavorable basis for comparison, since selection would have caused an underrepresentation of many diseases in the foundry population. In addition an external comparison cohort would have doubled the costs of the study. For these reasons the mortality of the foundry cohort was compared to that recorded for the general Finnish male population in the official statistics on causes of death in 1967 (19). The year 1967 was selected because most of the deaths occurred at the end of the $1960 \mathrm{~s}$. We also made internal comparisons within the occupational and exposure categories of workers.

For the comparisons between the foundry workers and the general male population, the standardized mortality ratio (SMR) and the proportional mortality figures were computed according to the cause of death. When different subcategories of the cohort were contrasted, a direct standardization method was used that employed the person-year distribution of one of the compared groups as the standard. However, since the age-structure of the subcohorts were similar, direct

Table 1. Proportion of subjects unlocated during the follow-up.

\begin{tabular}{|c|c|c|c|c|c|}
\hline \multirow{2}{*}{$\begin{array}{l}\text { Exposure } \\
\text { time (a) }\end{array}$} & \multirow{2}{*}{$\begin{array}{l}\text { Total } \\
\text { cohort }\end{array}$} & \multicolumn{2}{|c|}{ Unlocated } & \multicolumn{2}{|c|}{ Cause of death unknown } \\
\hline & & Number & $0 \%$ & Number & Reason \\
\hline$<1.0$ & 972 & 34 & 3.5 & 1 & died abroad \\
\hline $1.0-2.9$ & 1,042 & 3 & 0.3 & 1 & died abroad \\
\hline $3.0-4.9$ & 629 & 0 & 0.0 & - & - \\
\hline$\geq 5.0$ & 1,233 & 15 & 1.2 & 4 & died abroad \\
\hline Total & 3,876 & 52 & 1.3 & 6 & died abroad \\
\hline
\end{tabular}


standardization offered no great advantages over the SMR method.

In the study of lung cancer mortality we used a nested sampling design, i.e., a casereferent study imbedded in the cohort study. In this design the members of the original cohort formed the sampling roster from which the cases were selected and the referents ("controls") were sampled. The matching criterion was age, within 1-year limits. The exposure times were verified from questionnaires sent to the closest relatives of the cases and to the referents themselves.

In all, 20 of the relatives of the $21 \mathrm{pa}-$ tients who had died of lung cancer returned the questionnaire. While the employers' records gave an average exposure time of 5.1 years for the cases, the inquiries sent to the closest relatives gave one of 13.0 years. Thus the data recorded in the employers' records covered only $41 \%$ of the true exposure time, i.e., if the information obtained by the questionnaires

Table 2. Age-specific overall mortality among foundry workers from 1950 to 1973 in a comparison with the expected (Exp.) number of deaths, calculated from Finnish male population death rates. (Obs. $=$ observed; $S M R=$ standardized mortality ratio)

\begin{tabular}{|c|c|c|c|c|c|c|c|c|c|}
\hline \multirow[b]{2}{*}{ Age (a) } & \multicolumn{3}{|c|}{ All deaths } & \multicolumn{3}{|c|}{$<5$ years exposed } & \multicolumn{3}{|c|}{$\geq 5$ years exposed } \\
\hline & $\begin{array}{l}\text { Person- } \\
\text { years }\end{array}$ & Exp. & Obs. & $\begin{array}{c}\text { Person- } \\
\text { years }\end{array}$ & Exp. & Obs. & $\begin{array}{c}\text { Person- } \\
\text { years }\end{array}$ & Exp. & Obs. \\
\hline $15-24$ & 8,737 & 10.0 & $3 *$ & 8,162 & 9.4 & $2 * *$ & 575 & 0.7 & 1 \\
\hline $25-34$ & 16,778 & 31.0 & 29 & 13,039 & 24.1 & 24 & 3,739 & 6.9 & 5 \\
\hline $35-44$ & 12,866 & 57.4 & 59 & 8,125 & 36.3 & 34 & 4,741 & 21.2 & 25 \\
\hline $45-54$ & 6,233 & 70.5 & 69 & 3,506 & 39.7 & 42 & 2,727 & 30.9 & 27 \\
\hline $55-64$ & 2,184 & 57.7 & $39 *$ & 1,193 & 31.5 & 21 & 991 & 26.2 & 18 \\
\hline $65-74$ & 345 & 20.3 & 23 & 207 & 12.2 & 10 & 138 & 8.1 & 13 \\
\hline$\geq 75$ & 17 & 2.5 & 2 & 8 & 1.2 & 1 & 9 & 1.3 & 1 \\
\hline Total & 47,160 & 249.4 & 224 & 34,240 & 154.4 & 134 & 12,920 & 95.3 & 90 \\
\hline cohort & \multicolumn{3}{|c|}{$\mathrm{SMR}=90$} & \multicolumn{3}{|c|}{$\operatorname{SMR}=87$} & \multicolumn{3}{|c|}{$\mathrm{SMR}=94$} \\
\hline $\begin{array}{l}\text { Estimated } \\
\text { population a }\end{array}$ & 176,468 & $\begin{array}{r}796.7 \\
\mathrm{SMR}=\end{array}$ & 682 & 163,548 & $\begin{array}{l}701.7 \\
\mathrm{MR}=\end{array}$ & 592 & 12,920 & $\begin{array}{c}95.3 \\
\mathrm{MR}=94\end{array}$ & 90 \\
\hline
\end{tabular}

a Correlations were made for the respective sampling fractions in exposure time groups of less than 1 year and from 1 to 3 years.

$* \mathrm{p}<0.5$, Poisson distribution

$* * \mathrm{p}<0.01$

Table 3. Mortality of foundry workers from certain diseases in an age-specific comparison with the expected (Exp.) number of deaths, calculated from Finnish male population death rates. Cohort defined in the time period from 1950 to 1960 and followed-up until the end of 1973. (Obs. = observed)

\begin{tabular}{|c|c|c|c|c|c|c|c|c|c|c|c|c|c|}
\hline \multirow[t]{2}{*}{ Age (a) } & \multirow{2}{*}{$\begin{array}{l}\text { Person- } \\
\text { years }\end{array}$} & \multicolumn{2}{|c|}{ All deaths } & \multicolumn{2}{|c|}{$\begin{array}{c}\text { Coronary } \\
\text { heart } \\
\text { disease }\end{array}$} & \multicolumn{2}{|c|}{ Lung cancer } & \multicolumn{2}{|c|}{ Suicides } & \multicolumn{2}{|c|}{$\begin{array}{l}\text { Trans- } \\
\text { portation } \\
\text { accidents }\end{array}$} & \multicolumn{2}{|c|}{$\begin{array}{l}\text { Other } \\
\text { violent } \\
\text { deaths }\end{array}$} \\
\hline & & Exp. & Obs. & Exp. & Obs. & Exp. & Obs. & Exp. & Obs. & Exp. & Obs. & Exp. & Obs. \\
\hline $15-24$ & 2,919 & 3.3 & 1 & 0.0 & 1 & 0.0 & 0 & 0.5 & 0 & 1.4 & 0 & 0.6 & 0 \\
\hline $25-34$ & 8,809 & 16.3 & 16 & 1.2 & 0 & 0.1 & 0 & 3.0 & 5 & 4.1 & 2 & 2.6 & 4 \\
\hline $35-44$ & 9,007 & 40.2 & 50 & 10.7 & 9 & 1.1 & 3 & 4.6 & 5 & 4.2 & 7 & 5.6 & 8 \\
\hline $45-54$ & 4,493 & 50.8 & 47 & 21.1 & 20 & 3.0 & 3 & 3.0 & 1 & 2.4 & 1 & 3.3 & $8^{*}$ \\
\hline $55-64$ & 1,510 & 39.9 & $26 *$ & 15.8 & 12 & 4.3 & 4 & 1.0 & 2 & 0.9 & 0 & 1.0 & 0 \\
\hline $65-74$ & 253 & 14.9 & 19 & 5.4 & 5 & 1.2 & 3 & 0.2 & 0 & 0.2 & 1 & 0.2 & 0 \\
\hline$\geq 75$ & 22 & 3.2 & 1 & 1.0 & 0 & 0.1 & 0 & 0.0 & 0 & 0.0 & 0 & 0.0 & 0 \\
\hline
\end{tabular}

Total

Actual

sohort

$27,013 \quad 168.6 \quad 160$

$55.2 \quad 47$

$9.8 \quad 13$

$12.3 \quad 13$

$13.2 \quad 11$

13.320

${ }^{*} \mathrm{p}<0.05$, Poisson distribution 


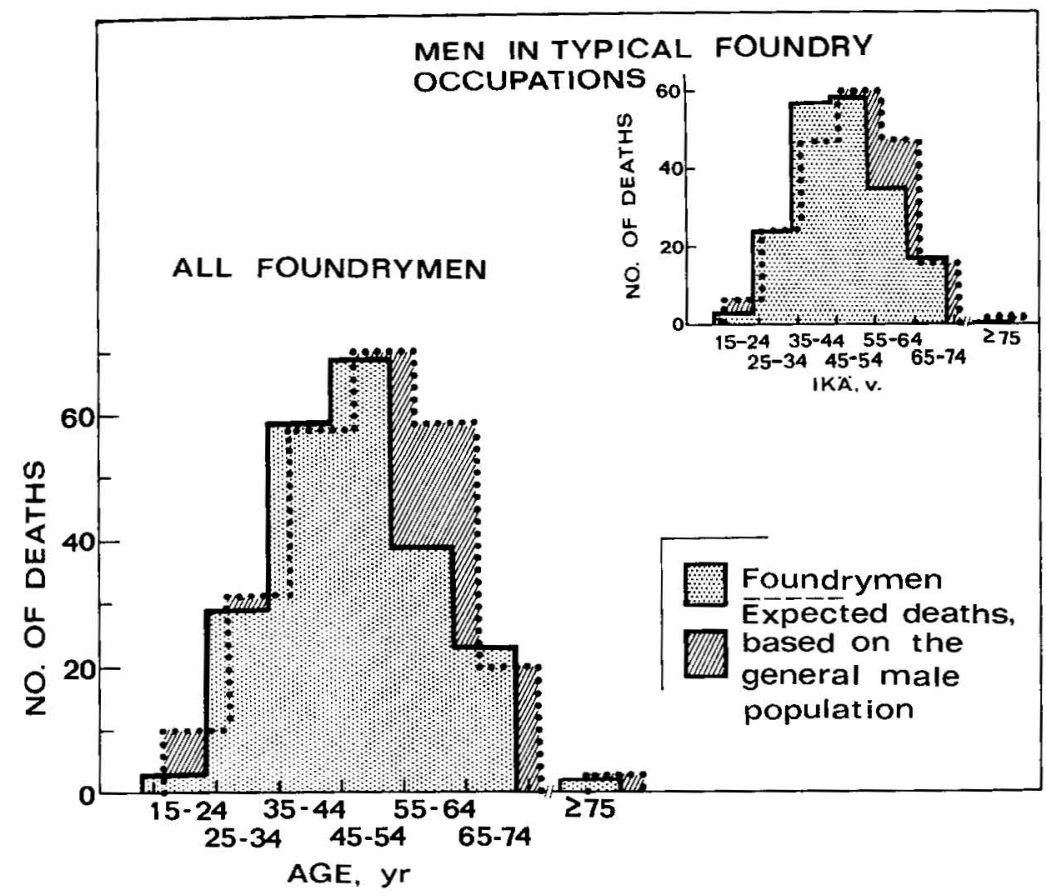

Fig. 2. Observed and expected number of deaths among foundry workers (actual cohort) by age from 1950 to 1973 .

was correct. The employers' records and the questionnaires agreed in 9 cases. The questionnaires gave a longer exposure time in 9 cases and a shorter one in 2 cases.

Fourteen of the 21 referents responded. Their average exposure time in the employers' records was 3.9 years, whereas it was 11.7 years according to the questionnaires. Thus the recorded data covered only $33 \%$ of the true exposure time. The records and the questionnaires gave the same exposure time in 7 cases, but the records gave a shorter exposure time in the remaining 7 cases.

\section{RESULTS}

\section{Total mortality}

Table 2 shows the observed and expected number of deaths among the foundry workers by age and exposure time. The SMR was 90 when the general male population was used as the reference. (The SMR of the general male population is defined as 100.) When the sampling fractions were employed for the shorter exposure categories, the SMR was 86. For those exposed for at least 5 years it was 96 . Because entry into the cohort was allowed until 1 year before the end of the follow-up, the "healthy worker effect" could be supposed to become emphasized in the latter part of it. To control this effect, we also computed the SMR separately for the first 11 years of follow-up. Since almost the same SMR, 94, was obtained and since no major differences prevailed for any specific cause of death, there was no reason to separate the different periods of the follow-up in the analysis of the data (table 3 ).

When only "typical" foundry occupations were considered, the SMR was 95. Patternmakers, inspectors, maintenance workers, and laborers assisting them were excluded as "atypical." In addition truck drivers, crane operators, and loader drivers were excluded because they were so few in number. The total mortality rates for all occupations and typical occupations are presented in fig. 2. Although the total mortality did not exceed the national figures in any age category, the distribution of deaths seemed to shift toward younger age groups (see especially the 35to 44-year age range versus the 55- to 64year age range in fig. 2). This shift was even more pronounced when only "typi- 


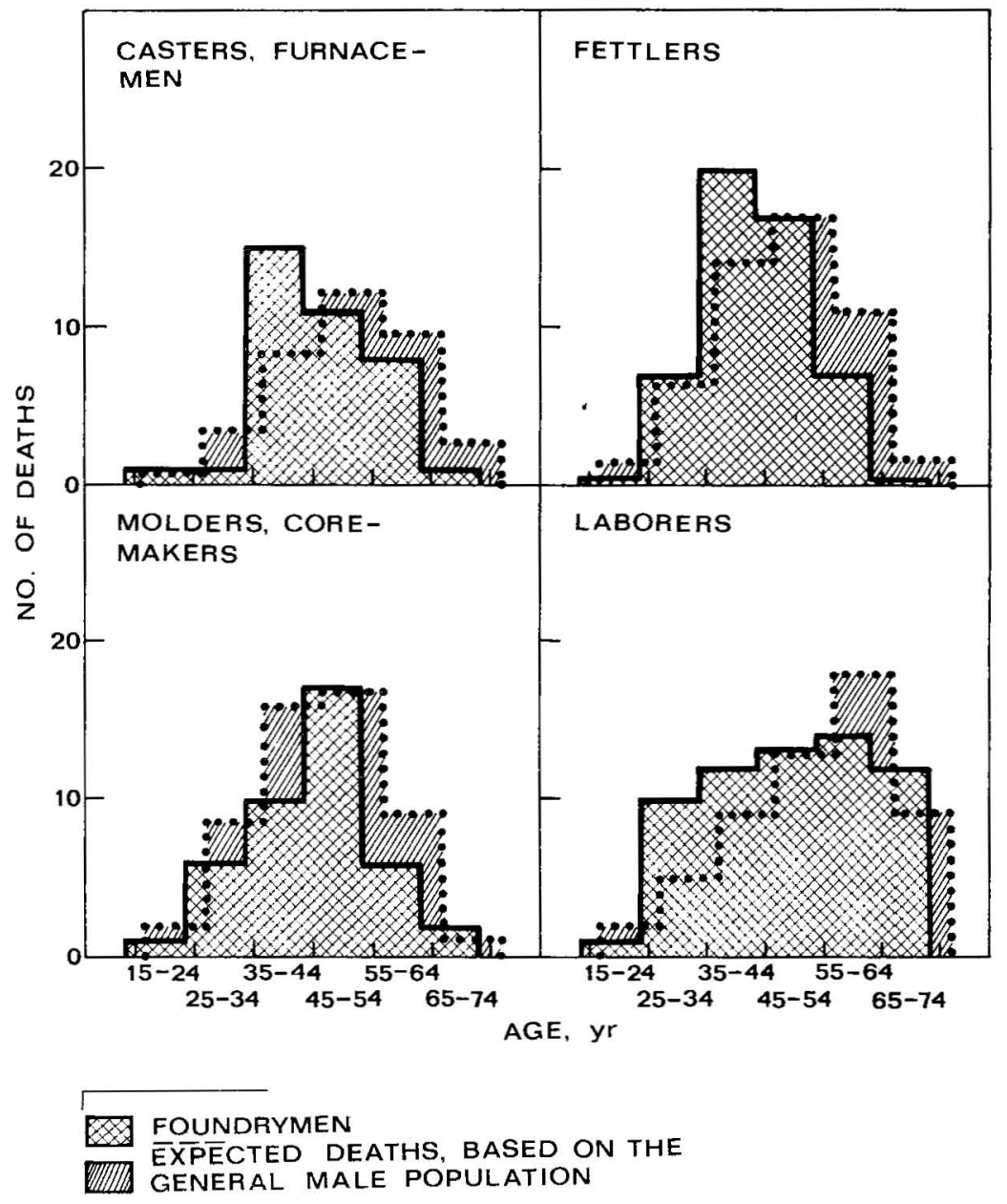

Fig. 3. Observed and expected number of deaths in certain occupational groups by age (actual cohort).

cal" foundry occupations were taken into consideration; the SMR was 110 for the 25- to 54-year age range. However, when tested with the Kolmogorov-Smirnov test, the shift did not reach common limits of statistical significance.

Grouping by occupation (fig. 3), i.e., dividing the material into homogeneous occupational groups of (a) casters and furnacemen, (b) fettlers, (c) molders and coremakers, and (d) common laborers, suggested that the shift, if present, could be attributed to the first two occupational groups. However common limits of statistical significance were not reached. A similar tendency also prevailed for the laborers, but it was directed toward even younger age groups (the 25- to 34-year and 35- to 44-year age ranges) and indicated that the distributions of the causes of death were perhaps different in that occupational group.

Stratification of the age-specific mortality data by exposure time yielded in SMR of $\mathbf{8 0}$ among workers exposed for less than 1 year, an SMR of 110 among those exposed from 5.0 to 10 years, but an SMR of 60 only among those exposed for more than 15 years (table 4). Using a Poisson distribution model for the occurrence of a small number of deaths, we tested the exposure-specific observed number of deaths for significance against the expected number, based on national figures. How- 
ever, the differences were not statistically significant. No remarkable differences with regard to total mortality between iron, steel, and nonferrous foundries existed, either. In this comparison the distribution of person-years in the nonferrous foundries was used as the standard.

\section{General aspects of the cause-specific mortality}

The most important cause-specific mortality data are compiled in table 5. Deaths from coronary heart disease were slightly less frequent than expected on the basis of the general population data, the SMR being 80. The same was true for other cardiovascular diseases, which had an SMR of 70 .
Most of the latter (21 cases) were cerebrovascular deaths (13 cases).

There was a slight excess of deaths from lung cancer. In all, 21 cases were observed against the expected 13.9. The $95 \%$ confidence limits were 13.0 and 32.1 , and the rate ratio was 1.5 . Two additional patients had died of lung cancer according to the physician's classification, but the deaths had been coded by the Central Statistical Office as coronary heart disease and tuberculosis of the lung, respectively. Because the Central Statistical Office's diagnoses were used throughout the study, these cases could not be included among the lung cancer cases. Mortality from other chronic respiratory diseases did not differ from the expected figures. Only in 9

Table 4. Overall mortality among foundry workers (actual cohort) in an exposure time specific comparison with the expected (Exp.) number of deaths, calculated from Finnish male population death rates. $(\mathrm{Obs} .=$ observed; $\mathrm{SMR}=$ stardardized mortality rate)

\begin{tabular}{|c|c|c|c|c|c|}
\hline $\begin{array}{l}\text { Exposure } \\
\text { time (a) }\end{array}$ & Person-years & Exp. & Obs. & SMR & $\begin{array}{c}95 \% \text { confidence } \\
\text { limits }\end{array}$ \\
\hline$<1.0$ & 12,863 & 54.2 & 45 & 83 & $61-111$ \\
\hline $1.0-2.0$ & 13,496 & 59.5 & 53 & 89 & $67-117$ \\
\hline $3.0-4.9$ & 7,376 & 40.6 & 36 & 89 & $62-123$ \\
\hline $5.0-9.9$ & 8,575 & 53.5 & 61 & 114 & $87-146$ \\
\hline $10.0-14.9$ & 2,920 & 24.7 & 18 & 73 & $43-115$ \\
\hline$\geq 15.0$ & 1,425 & 17.0 & 11 & 65 & $32-116$ \\
\hline \multicolumn{6}{|l|}{ Total } \\
\hline Actual & & & & & \\
\hline cohort & 47,160 & 249.5 & 224 & 90 & $77-101$ \\
\hline
\end{tabular}

Table 5. Mortality among foundry workers in certain disease classifications (in the period from 1950 to 1973) in a comparison with the expected (Exp.) number of deaths, calculated from Finnish male population death rates. (Obs. - observed; SMR $=$ standardized mortality ratio)

\begin{tabular}{|c|c|c|c|c|c|c|c|c|c|c|c|}
\hline \multirow{2}{*}{ Age (a) } & \multirow{2}{*}{$\begin{array}{l}\text { Person- } \\
\text { years }\end{array}$} & \multicolumn{2}{|c|}{$\begin{array}{c}\text { Coronary heart } \\
\text { disease }\end{array}$} & \multicolumn{2}{|c|}{$\begin{array}{l}\text { Lung } \\
\text { cancer }\end{array}$} & \multicolumn{2}{|c|}{ Suicides } & \multicolumn{2}{|c|}{$\begin{array}{l}\text { Transporta- } \\
\text { tion accidents }\end{array}$} & \multicolumn{2}{|c|}{$\begin{array}{l}\text { Other violent } \\
\text { deaths }\end{array}$} \\
\hline & & Exp. & Obs. & Exp. & Obs. & Exp. & Obs. & Exp. & Obs. & Exp. & Obs. \\
\hline $15-24$ & 8,737 & 0.1 & 1 & 0.0 & 0 & 1.6 & 0 & 4.2 & 0 & 1.7 & 1 \\
\hline $25-34$ & 16,778 & 2.2 & 2 & 0.3 & 1 & 5.6 & 11 & 7.8 & 4 & 4.9 & 6 \\
\hline $35-44$ & 12,866 & 15.2 & 10 & 1.6 & 3 & 6.6 & 7 & 6.0 & 8 & 8.0 & 11 \\
\hline $45-54$ & 6,233 & 29.2 & 28 & 4.1 & 6 & 4.2 & 3 & 3.4 & 2 & 4.5 & 6 \\
\hline $55-64$ & 2,184 & 22.8 & 16 & 6.2 & 7 & 1.5 & 2 & 1.3 & 0 & 1.4 & 2 \\
\hline $65-74$ & 345 & 7.4 & 9 & 1.6 & 4 & 0.2 & 0 & 0.3 & 2 & 0.3 & 0 \\
\hline$\geq 75$ & 17 & 0.8 & 0 & 0.1 & 0 & 0.0 & 0 & 0.0 & 0 & 0.0 & 0 \\
\hline \multicolumn{12}{|l|}{ Total } \\
\hline Actual & 47,160 & \multirow{2}{*}{\multicolumn{2}{|c|}{$\mathrm{SMR}=85$}} & \multirow{2}{*}{\multicolumn{2}{|c|}{$\begin{array}{l}13.9=21 \\
\text { SMR }=151\end{array}$}} & \multirow{2}{*}{\multicolumn{2}{|c|}{$\begin{array}{lc}19.7 & 23 \\
\text { SMIR } & =117\end{array}$}} & \multirow{2}{*}{\multicolumn{2}{|c|}{$\begin{array}{l}23.0 \quad 16 \\
S M R=70\end{array}$}} & \multirow{2}{*}{\multicolumn{2}{|c|}{$\begin{array}{lc}20.8 & 26 \\
\text { SMIR } & =125\end{array}$}} \\
\hline cohort & & & & & & & & & & & \\
\hline $\begin{array}{l}\text { Estimated } \\
\text { population }\end{array}$ & 176,468 & \multicolumn{2}{|c|}{$\begin{array}{r}232.0 \quad 197 \\
\text { SMR }=85\end{array}$} & \multicolumn{2}{|c|}{$\begin{array}{l}42.2=61 \\
\text { SMR }=145\end{array}$} & \multicolumn{2}{|c|}{$\begin{array}{l}69.1 \quad 69 \\
\text { SMR }=100\end{array}$} & \multicolumn{2}{|c|}{$\begin{array}{lc}84.4 & 97 \\
\text { SMR } & =115\end{array}$} & \multicolumn{2}{|c|}{$\begin{array}{lc}73.1 & 99 \\
\text { SMR } & =135\end{array}$} \\
\hline
\end{tabular}


cases was some respiratory disease (excluding tuberculosis) noted on the certificate as the immediate, or an intermediate, cause of death. Cor pulmonale was mentioned twice as a secondary cause; and chronic bronchitis, once as a primary and twice as a secondary cause. Emphysema
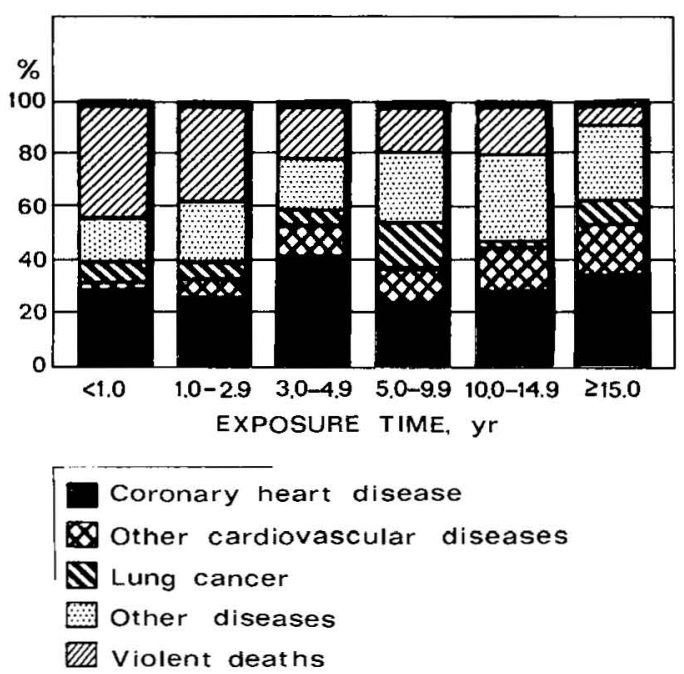

Fig. 4. Proportional mortality of foundry workers according to cause of death and exposure time categories (actual cohort). occurred 7 times as a secondary cause. Seven certificates mentioned pneumonia, and in 2 cases it was the primary cause of death. Lung tuberculosis was noted in 2 cases as the primary and in 6 cases as a secondary cause.

The total number of violent deaths did not differ from the expected figure. Most violent deaths were suicides; transportation accidents came next (table 5). Only two fatal work accidents had occurred.

We further analyzed the cause-specific mortality by comparing the proportional mortality in different exposure time categories (fig. 4). The proportion of violent deaths decreased as the exposure time increased. The frequency peak for coronary mortality occurred among those exposed for 3 to 5 years, while mortality from other cardiovascular diseases increased steadily with the duration of exposure. The proportional lung cancer mortality was the highest in the 5- to $10-$ year exposure category.

\section{Lung cancer mortality}

As stated earlier, the foundry workers' age-specific mortality from lung cancer was slightly higher than expected on the

Table 6. Lung cancer mortality of foundry workers in a comparison with the age-specific expected number of deaths, calculated from Finnish male population proportional mortality.

\begin{tabular}{llll}
\hline Age (a) & General male population & & Foundry workers \\
\cline { 5 - 6 } $\begin{array}{c}\text { Proportion of lung cancer } \\
\text { deaths from all deaths }(\%)\end{array}$ & All deaths & $\begin{array}{c}\text { Expected number } \\
\text { of lung cancer } \\
\text { deaths a }\end{array}$ & $\begin{array}{l}\text { Observed lung } \\
\text { cancer cases }\end{array}$
\end{tabular}

\begin{tabular}{|c|c|c|c|c|}
\hline & (1) & (2) & (3) & (4) \\
\hline $15-24$ & 0.0 & 3 & 0.0 & 0 \\
\hline $25-34$ & 0.9 & 29 & 0.3 & 1 \\
\hline $35-44$ & 2.8 & 59 & 1.7 & 3 \\
\hline $45-54$ & 5.8 & 69 & 4.0 & 6 \\
\hline $55-64$ & 10.8 & 39 & 4.2 & 7 \\
\hline $65-74$ & 8.0 & 23 & 1.8 & 4 \\
\hline$\geq 75$ & 2.8 & 2 & 0.1 & 0 \\
\hline \multicolumn{5}{|l|}{ Total } \\
\hline cohort & 6.5 & 224 & 12.1 & $21 *$ \\
\hline $\begin{array}{l}\text { Estimated } \\
\text { population }\end{array}$ & 6.5 & 682 & 34.2 & 61 \\
\hline
\end{tabular}

a The expected numbers in column 3 have been calculated by multiplying the numbers in column

1 by those in column 2 .

* $\mathrm{p}<0.05$, Poisson distribution 
Table 7. Lung cancer mortality of foundry workers in exposure time groups of less than 5 years and 5 years and over in a comparison with the expected (Exp.) number of deaths, calculated from Finnish male population death rates. (Obs. = observed)

\begin{tabular}{|c|c|c|c|c|c|c|c|c|c|}
\hline \multirow{2}{*}{ Age (a) } & \multicolumn{3}{|c|}{5 years exposed } & \multicolumn{3}{|c|}{$\geq 5$ years exposed } & \multicolumn{3}{|c|}{$\begin{array}{c}\text { Typical foundry occupa- } \\
\text { tions } \geq \mathbf{5} \text { years } \\
\text { exposed }\end{array}$} \\
\hline & $\begin{array}{l}\text { Person- } \\
\text { years }\end{array}$ & Exp. & Obs. & $\begin{array}{l}\text { Person- } \\
\text { years }\end{array}$ & Exp. & Obs. & $\begin{array}{l}\text { Person- } \\
\text { years }\end{array}$ & Exp. & Obs. \\
\hline $15-24$ & 8,162 & 0.0 & 0 & 575 & 0.0 & 0 & 448 & 0.0 & 0 \\
\hline $25-34$ & 13,039 & 0.2 & 0 & 3,739 & 0.1 & 1 & 3,067 & 0.0 & 1 \\
\hline $35-44$ & 8,125 & 1.0 & 2 & 4,741 & 0.6 & 1 & 4,046 & 0.5 & 1 \\
\hline $45-54$ & 3,506 & 2.3 & 2 & 2,727 & 1.8 & 4 & 2,343 & 1.5 & 3 \\
\hline $65-74$ & 1,193 & 3.4 & 3 & 991 & 2.8 & 4 & 809 & 2.3 & 4 \\
\hline $55-64$ & 207 & 1.0 & 3 & 138 & 0.6 & 1 & 104 & 0.5 & 1 \\
\hline$\geq 75$ & 8 & 0.0 & 0 & 9 & 0.0 & 0 & 9 & 0.0 & 0 \\
\hline \multicolumn{10}{|l|}{ Total } \\
\hline $\begin{array}{l}\text { Actual } \\
\text { cohort }\end{array}$ & 34,240 & 7.9 & 10 & 12,920 & 5.9 & 11 & 10,826 & 4.8 & 10 \\
\hline
\end{tabular}

Table 8. Lung cancer mortality among those exposed a minimum of $\mathbf{5}$ years, by type of foundry, in a comparison with the expected (Exp.) number of deaths, calculated from Finnish male population death rates. (Obs. $=$ observed)

\begin{tabular}{|c|c|c|c|c|c|c|c|c|c|}
\hline \multirow[b]{2}{*}{ Age (a) } & \multicolumn{3}{|c|}{ Iron foundries } & \multicolumn{3}{|c|}{ Steel foundries } & \multicolumn{3}{|c|}{ Nonferrous foundries } \\
\hline & $\begin{array}{l}\text { Person- } \\
\text { years }\end{array}$ & Exp. & Obs. & $\begin{array}{l}\text { Person- } \\
\text { years }\end{array}$ & Exp. & Obs. & $\begin{array}{l}\text { Person- } \\
\text { years }\end{array}$ & Exp. & Obs. \\
\hline $15-24$ & 293 & 0.0 & 0 & 208 & 0.0 & 0 & 51 & 0.0 & 0 \\
\hline $25-34$ & 2,123 & 0.0 & 1 & 1,267 & 0.0 & 0 & 331 & 0.0 & 0 \\
\hline $35-44$ & 2,727 & 0.3 & 1 & 1,526 & 0.2 & 0 & 407 & 0.1 & 0 \\
\hline $45-54$ & 1,647 & 1.1 & 4 & 721 & 0.5 & 0 & 312 & 0.2 & 0 \\
\hline $55-64$ & 638 & 1.8 & 3 & 248 & 0.7 & 0 & 98 & 0.3 & 1 \\
\hline $65-74$ & 111 & 0.5 & 0 & 16 & 0.1 & 0 & 14 & 0.1 & 0 \\
\hline$\geq 75$ & 10 & 0.0 & 1 & - & - & - & - & - & - \\
\hline Total & 7,549 & 3.7 & $10 *$ & 3,986 & 1.5 & 0 & 1,213 & 0.7 & 1 \\
\hline
\end{tabular}

$* \mathrm{p}<0.05$, Poisson distribution

basis of the general population data (table $5)$, but it did not reach common levels of significance. However the result became significant when proportional mortality figures were used ( $p<0.05$, Poisson distribution, table 6 ).

Because occupational cancers may show dose-response relationships, lung cancer mortality rates were calculated separately for those exposed for less than 5 years and for those exposed for 5 years or more (table 7). For all those exposed for more than 5 years, the rate was 1.9 times and, for those in typical foundry occupations, it was 2.1 times the expected value. For those exposed for less than 5 years it was only 1.3 times the expected value.

We also attempted to analyze the lung cancer mortality by allowing for some induction time. However an induction time of 15 years would have left only 5 lung cancer cases; and one of 10 years, 9 cases. Furthermore, because the information on the duration of employment was underestimated in the employers' records and because correct data were available only for the cases and their referents, it was not meaningful to analyze the lung cancer mortality with induction time taken into account. 
Table 9. Lung cancer mortality among foundry workers (actual cohort) according to the dustiness of the work and the grouping of exposure (less than 5 years and at least 5 years) compared with the expected number of deaths, calculated from Finnish male population death rates.

\begin{tabular}{lrrc}
\hline Exposure category & $\begin{array}{c}\text { Person- } \\
\text { years }\end{array}$ & Exp. & Obs. \\
\hline 5 years exposed & 19,218 & 5.3 & 9 \\
Slight dust & 15,022 & 2.6 & 1 \\
High dust & & & \\
$\geq 5$ years exposed & 5,454 & 3.0 & 3 \\
Slight dust & 7,466 & 2.9 & $8^{*}$ \\
High dust & \\
\hline
\end{tabular}

$* \mathrm{p}<0.05$, Poisson distribution

Lung cancer mortality was higher in iron foundries than in foundries of other types. Sixteen of the 21 cases had occurred in iron foundries, 3 in foundries casting both iron and other metals, 1 in a nonferrous foundry, and 1 in a steel foundry. When the general male population was used as the standard, the SMR was the highest $(270,95 \%$ confidence limits $130-$ 497) among iron foundry workers exposed for at least 5 years (table 8).

The lung cancer mortality was further studied through the classification of workers according to dust exposure (8). Among those who had worked for at least 5 years in jobs classified as dusty, lung cancer was more frequent $(p<0.05$, Poisson distribution) than among workers with less than 5 years of exposure in less dusty environments (table 9). A more detailed analysis revealed that the cases in the higher ex- posure category derived from two occupational groups, namely, molders plus coremakers and fettlers (table 10). Even though the former group was made up of two different occupations, all the cases had been molders. Hence the molders' overmortality was even higher than what appeared in the classification.

The results thus suggested that lung cancer mortality was the highest in iron foundries, especially among molders. Additional analyses, using a different approach, were introduced to test this hypothesis. In these analyses only the workers exposed for more than 5 years were included. The hypothesis to be tested was that exposure in iron foundries was different from exposure in steel and nonferrous foundries and this difference in exposure had caused the increased lung cancer incidence in iron foundries. The hypothesis was tested with a standard Normal test statistic with Binomial moments. The total number of lung cancer cases, 10 , yielded a two-sided p-value of 0.014 . Thus the lung cancer mortality in iron foundries deviated significantly from the corresponding figures in steel and nonferrous foundries.

In order to verify the observed excess of lung cancer mortality among molders exposed for 5 years or more, we studied case-history data in detail to determine whether molders were more frequent among the cases than among the referents. The distribution of cases and referents into molders and other occupations is shown in table 11. The significance testing of the association of lung cancer mortality and exposure history was based on a hyper-

Table 10. Lung cancer mortality of foundry workers (actual cohort) by occupational group and exposure time classification in a comparison with the expected (Exp.) number of deaths, calculated from the Finnish male population death rates (based on age-specific rates). (Obs. = observed)

\begin{tabular}{|c|c|c|c|c|c|c|}
\hline \multirow{2}{*}{ Occupational group } & \multicolumn{2}{|c|}{ Lung cancer } & \multicolumn{2}{|c|}{$<5$ years exposed } & \multicolumn{2}{|c|}{$\geq 5$ years exposed } \\
\hline & Exp. & Obs. & Exp. & Obs. & Exp. & Obs. \\
\hline Molders and coremakers & 2.7 & 6 & 1.1 & 1 & 1.5 & $5 *$ \\
\hline Casters and furnacemen & 2.1 & 5 & 1.0 & $4 *$ & 1.1 & 1 \\
\hline Fettlers & 2.9 & 3 & 1.4 & 0 & 1.3 & 3 \\
\hline Laborers & 3.7 & 5 & 2.7 & 4 & 0.9 & 1 \\
\hline
\end{tabular}

$* \mathrm{p}<0.05$, Poisson distribution 
geometric model for the distribution of the cases in molding and other occupations. The model gave a two-sided p-value of 0.026. Hence there were significantly more molders among those lung cancer cases with an employment of more than 5 years than among their age-matched referents.

\section{Mortality from coronary heart disease}

Altogether 66 deaths were caused by coronary heart disease, 12 of which had occurred during employment in a foundry. The age-standardized mortality rate did not exceed the expected one obtained from national figures, neither for the total group nor for any single age category (table 5). Analysis of the proportional mortality gave a similar result; in $34 \%$ of the general male population coronary heart disease was the primary cause of death. Therefore, the expected number of cases was 71 (table 12). The coronary mortality showed no concentration in any special exposure-time category irrespective of the method of analysis.

Table 11. Distribution of cases and referents with more than 5 years of exposure into molders and other occupations.

\begin{tabular}{lccc}
\hline & Molders & $\begin{array}{c}\text { Other } \\
\text { occupations }\end{array}$ & Total \\
\hline Lung cancer & 5 & 5 & 10 \\
Controls & 0 & 10 & 10 \\
\hline Total & 5 & 15 & 20 \\
\hline
\end{tabular}

Table 12. Coronary heart disease mortality of foundry workers in a comparison with the expected number of deaths, calculated on the basis of the age-specific proportion of death rates from the Finnish male population.

\begin{tabular}{|c|c|c|c|c|}
\hline \multirow[b]{2}{*}{ Age (a) } & \multirow{2}{*}{$\begin{array}{c}\text { General male population } \\
\begin{array}{c}\text { Proportion of coronary } \\
\text { deaths from all } \\
\text { deaths }(\%)\end{array}\end{array}$} & \multicolumn{3}{|c|}{ Foundry workers } \\
\hline & & All deaths & $\begin{array}{c}\text { Expected number } \\
\text { of coronary } \\
\text { deaths }{ }^{a}\end{array}$ & $\begin{array}{c}\text { Observed } \\
\text { coronary deaths }\end{array}$ \\
\hline
\end{tabular}

\begin{tabular}{|c|c|c|c|c|}
\hline & (1) & (2) & (3) & (4) \\
\hline $\begin{array}{c}15-24 \\
25-34 \\
35-44 \\
45-54 \\
55-64 \\
65-74 \\
\geq 75\end{array}$ & $\begin{array}{r}1.0 \\
7.1 \\
26.5 \\
41.4 \\
39.6 \\
36.7 \\
30.2\end{array}$ & $\begin{array}{r}3 \\
29 \\
59 \\
69 \\
39 \\
23 \\
2\end{array}$ & $\begin{array}{r}0.0 \\
2.1 \\
15.6 \\
28.6 \\
15.4 \\
8.4 \\
0.6\end{array}$ & $\begin{array}{r}1 \\
2 \\
10 \\
28 \\
16 \\
9 \\
0\end{array}$ \\
\hline $\begin{array}{l}\text { Total } \\
\text { Actual } \\
\text { cohort }\end{array}$ & 34.2 & 224 & 70.7 & 66 \\
\hline $\begin{array}{l}\text { Estimated } \\
\text { population }\end{array}$ & 34.2 & 682 & 208.7 & 197 \\
\hline
\end{tabular}

a The expected numbers in column 3 have been calculated by multiplying the numbers in column 1 by those in column 2 .

Table 13. Coronary heart disease mortality of foundry workers (actual cohort) by type of foundry in a comparison with the expected number of deaths, calculated from Finnish male population death rates. (SMR $=$ standardized mortality rate)

\begin{tabular}{lcrrrr}
\hline Type of foundry & Person-years & Expected & Observed & SMR & $\begin{array}{c}\text { 95 confidence } \\
\text { limits }\end{array}$ \\
\hline Iron foundry & 28,806 & 49.5 & 43 & 87 & $63-117$ \\
Steel foundry & 13,346 & 18.6 & 19 & 102 & $62-160$ \\
Nonferrous foundry & 4,720 & 9.5 & 4 & 42 & $12-108$ \\
\hline Total & 46,872 & 77.6 & 66 & 85 & $66-108$ \\
\hline
\end{tabular}


The coronary mortality, as stratified by type of foundry, is shown in table 13 . The SMR was 102 in steel foundries, 87 in iron foundries, and 42 in nonferrous foundries. When direct standardization was used, coronary mortality was also the highest in steel foundries and the lowest in nonferrous foundries, but none of the differences were statistically significant.

We also analyzed coronary mortality by arranging the occupations according to carbon monoxide exposure (table 14). There were no significant differences between the carbon monoxide exposure categories. The coronary mortality was the highest (SMR 100) for coremakers and molders, the second highest for casters and furnacemen (SMR 90), the third highest for fettlers (SMR 80), and the lowest for laborers (SMR 50).

The only significant result was the lower than expected mortality for laborers $(p<$ 0.05). No significant deviation from the expected figures could be observed in any age or exposure category. Neither did the directly standardized rates (with the experience of "typical foundry occupations" as standard) for the occupational groups deviate significantly from each other (table 15).

\section{Violent deaths}

Altogether 65 violent deaths occurred during the follow-up period. Most of them were suicides, 23 , or transportation accidents, 16. Violent deaths seemed to be more frequent in the younger age groups. This tendency was the most marked for suicides, but it did not reach statistical significance (table 5). Alcohol was a contributing factor in every third violent death. Fig. 4 also shows that the proportion of violent deaths decreased with increasing exposure time. It was the highest for those exposed for less than 1 year and the lowest among those exposed for more than 15 years.

Analysis by occupation, age, and exposure revealed that violent deaths were less frequent than expected for the coremakers and molders (table 16). On the contrary, mortality from "other violent causes" was 2.4 times the expected value for casters and furnacemen $(p<0.05$,
Poisson distribution). The excess was the greatest for the 45- to 54-year age range and the 1- to 3-year exposure category, but the number of cases in the age and exposure categories was low. Mortality from "other violent causes" was nearly twice the expected value also among the fettlers, but the difference was not statistically significant. The observed number of suicides and transportation accidents for casters and furnacemen and for fettlers did not exceed the expected figures. Among the laborers the frequency of suicides was 2.4 times the expected value ( $p<0.05$, Poisson distribution). The excess originated mainly from the 25- to 54-year age range $(p<0.05)$ and the 1 - to 3 -year exposure category $(p<0.01)$. For the laborers "other violent deaths" exceeded the expected value $(p<0.01$, Poisson distribution). The excess occurred in the 25 - to 64-year age range $(\mathrm{p}<0.01)$ and in the 3-month to 3-year exposure category $(\mathrm{p}<0.01)$.

\section{DISCUSSION}

It has often been stated that most occupational cohorts are selected with regard to life expectancy as compared with the entire general population, which comprises all those who have never been fit to work, those incapacitated soon after having reached the working age, and, in addition, asocial individuals. This selection has been named the "healthy worker effect."

In a recent study, Kitigawa and Hauser (9) found that $4.3 \%$ of the total working age population had never been employed. The SMR of this population segment was 204. An additional 4\% was unemployed at the time of the investigation; their SMR was 125 . The SMR for the remaining 91.7 $\%$ was 95 . When allowance was made for the fact that the proportion of unemployed persons rose with age, the corrected SMR of the active population became as low as 85. This result agrees with results obtained from a number of occupational cohorts. For example, a steelworkers' cohort showed an SMR of 82 (11) and a rubber workers' cohort one of 87 for the age groups 45 to 54 years (13). Similar results have been obtained at our institute. A study of road and building contractors yielded an SMR 
of 76 (14), a granite workers' cohort one of 85 (1), and a dock workers' cohort one of 81 (2). The two last mentioned cohorts represent occupations generally regarded as demanding. These examples clearly show that mortality becomes underestimated when the general population is used for reference.

The healthy worker effect is however not the same for all causes of death. For example, when cancer is concerned, selection does not play an important role (5). Hence the general population is adequate for comparison in studies of occupational cancer as far as the healthy worker effect is concerned, but other circumstances, such as regional differences in cancer mortality, create other problems. The healthy worker effect is the strongest at the beginning of employment. In a mortality study of asbestos product workers Enterline (4) found SMRs of 95, 112, and 123, respectively, for three consecutive 5-year followup periods. These examples show that several different factors indeed influence the healthy worker effect.

Table 14. Coronary heart disease mortality of foundry workers (actual cohort) by the degree of carbon monoxide (CO) pollution present in work in a comparison with the expected number of deaths, calculated from Finnish male population death rates. (SMR $=$ standardized mortality rate)

\begin{tabular}{lccccc}
\hline Exposure category & Person-years & Expected & Observed & SMR & $\begin{array}{c}95 \% \text { confidence } \\
\text { limits }\end{array}$ \\
\hline CO exposure & 6,089 & 12.3 & 11 & 89 & $45-160$ \\
Occasional CO exposure & 18,885 & 35.7 & 26 & 73 & $48-107$ \\
No CO exposure & 22,186 & 29.9 & 29 & 97 & $65-139$ \\
\hline Total & 47,160 & 77.9 & 66 & 85 & $66-108$ \\
\hline
\end{tabular}

Table 15. Coronary heart disease mortality of foundry. workers (actual cohort) by occupational groups. Standardization of death rates was performed with the age-structure of the typical foundry occupations as the standard.

\begin{tabular}{|c|c|c|c|c|}
\hline Occupational groups & Person-years & Observed & $\begin{array}{l}\text { Incidence rate/ } \\
100 \text { person-years }\end{array}$ & $\begin{array}{l}\text { Standardized } \\
\text { rate in units } \\
\text { of } 1 / 1000 \\
\text { person-years }\end{array}$ \\
\hline Molders and coremakers & 12,320 & 16 & 1.3 & 2.1 \\
\hline Casters and furnacemen & 6,089 & 11 & 1.8 & 1.5 \\
\hline Fettlers & 10,168 & 14 & 1.4 & 1.3 \\
\hline Laborers & 8,717 & 10 & 1.1 & 0.9 \\
\hline
\end{tabular}

Table 16. Mortality of foundry workers by violent causes in certain occupational groups (actual cohort) in a comparison with the exposed (Exp.) number of deaths, calculated from Finnish male population death rates. (Obs. = observed)

\begin{tabular}{|c|c|c|c|c|c|c|c|}
\hline \multirow{2}{*}{ Occupational group } & \multirow{2}{*}{ Person-years } & \multicolumn{2}{|c|}{ Suicides } & \multicolumn{2}{|c|}{$\begin{array}{c}\text { Transportation } \\
\text { accidents }\end{array}$} & \multicolumn{2}{|c|}{$\begin{array}{c}\text { Other violent } \\
\text { deaths }\end{array}$} \\
\hline & & Exp. & Obs. & Exp. & Obs. & Exp. & Obs. \\
\hline Molders and coremakers & 12,320 & 5.0 & 3 & 6.0 & 5 & 5.4 & 2 \\
\hline Casters and furnacemen & 6,089 & 2.6 & 2 & 3.0 & 3 & 2.9 & $8 *$ \\
\hline Fettlers & 10,168 & 4.4 & 6 & 5.0 & 0 * & 4.8 & 9 \\
\hline Laborers & 8,717 & 3.8 & $9 *$ & 4.3 & 7 & 3.8 & $12 * *$ \\
\hline
\end{tabular}

$* \mathrm{p}<0.05$, Poisson distribution

$* * \mathrm{p}<0.01$ 
In the present study entry into the cohort was permitted for a period of 23 years (1950 through 1972). The cohort also comprised foundry workers who left foundry work. With such a design previously and presently employed workers can be studied separately, but the healthy worker effect becomes emphasized because an unduly high proportion of the workers will have a short follow-up period. However mortality analysis based on personyears diminishes that effect, since those who enter the cohort at the end of the follow-up have fewer person-years and weigh less than those followed from the beginning. In the present study the latter circumstance actually almost neutralized the effect of the short follow-up; the SMR calculated separately for those who entered the cohort from 1950 through 1960 was only slightly higher than that for the entire cohort.

The foundry workers had a high turnover, which mostly depended on economic fluctuations (10), but possible annual variations in the selection at employment were balanced by the sampling method, which favored longer exposure categories, and partly also by the long period of entry into the cohort (fig. 1). However turnover may, at least to some extent, have been selective. Such selection tends to strengthen the healthy worker effect at least in certain jobs. For example, carbon monoxide or dust exposure may force sensitive individuals to seek other employment, because their effects are, to some extent, discernible. In fact workers in occupations classified as dusty turned out to have a higher turnover and, consequently, a shorter average exposure time than those in other occupations (10).

Against this background, it is difficult to conclude whether the SMR of 95 for workers in "typical" foundry occupations is higher than could be expected from an occupational cohort with rather demanding work; i.e., does there exist some occupational factor(s) which increases the mortality of foundry workers? In light of the fact that most occupational cohorts have SMRs that are well below 90 , it is hard to avoid the impression that the mortality in the present cohort indeed was slightly elevated. Especially the SMR of 110 found in the 25- to 54-year category of "typical" foundry workers seems high. Statistical significance is no meaningful concept in this context if the premise that occupational cohorts "normally" should have SMRs below 90 is correct, since the null nypothesis supposes an SMR of 100 .

\section{Lung cancer mortality}

To our knowledge, lung cancer mortality among foundry workers has not been studied earlier with epidemiologic methods. The only reference is made by McLaughlin and Harding (12), who observed a high frequency of bronchial cancer in an autopsy material. They proposed occupational exposure to carcinogenic factors as an explanation, but were not able to specify those factors. In steelworkers an excess lung cancer mortality has been found among coke oven workers. Those working at the top of the ovens had a sevenfold lung cancer mortality as compared to the reference group (15). Polycyclic aromatic compounds liberated from burning coke were considered to be the cause. However, the work conditions in steel works differ so much from those in foundries that no straightforward parallels can be drawn. Hence the increased risk of dying from lung cancer found in this study among workers in iron foundries, especially among the molders, seems to be a new experience. The question arises of what could be the reason for such an excess.

In iron foundries the molding sand is mixed with coal dust, and sometimes with pitch, and a number of organic materials are used as binders. When these components are heated, polycyclic aromatic compounds are liberated and released into the ambient air. According to Czechoslovakian and Japanese studies high concentrations of 3,4 benzopyrene have been measured in connection with molding (16, 20). It is remarkable that this compound could be found in great amounts (0.6-4.1 $\mu \mathrm{g} / \mathrm{m}^{3}$ ) even when the raw materials did not contain any of it (16). The most likely explanation is that the organic materials used as binders form 3,4 benzopyrene and perhaps other aromatic compounds as well - when heated under pressure and that these compounds then become ab- 
sorbed on the surface of the dust particles (3). However, since we did not have enough knowledge to suspect excess lung cancer prior to our study, no measurements of carcinogenic substances were included in the project; hence we have no such data yet available to explain our findings.

The risk for lung cancer was the highest for workers exposed for at least 5 years in iron foundries, especially for molders. Even though statistically significant as such, these results in fact are underestimates. First, some metal foundries actually did iron founding in addition to nonferrous founding. Those workers involved should have been classified as iron foundry workers. We became aware of the problem after the study was completed, because detailed investigation of the cases in connection with the casereferent analysis showed that 3 of 4 cases observed in "nonferrous" foundries had actually been engaged in casting iron. Such a thorough scrutinization could not be done for the whole cohort for practical reasons, and therefore correct reclassifications could not be made in retrospect. Consequently the lung cancer risk became overestimated in nonferrous foundries and underestimated in iron foundries. In reality there was only one lung cancer case in the former. Second, molders and coremakers were combined into one occupational category. Still all patients with lung cancer in this category had been molders, as revealed by the case-referent approach. If the coremakers' person-years (whose proportion of the total category was about $20 \%$, as estimated from the questionnaires) had been excluded, the molders' risk would have become even more pronounced. Third, there were two additional lung cancer cases classified as primary causes of death by the physician, but as secondary causes by the Central Statistical Office; those cases had to be omitted for reasons of uniformity.

In studies of lung cancer, the smoking habits of the cohorts should be checked. Although the hospital records were not completely satisfactory, this could be done for the 21 lung cancer cases. Only one of them had never smoked. This finding is by no means exceptional because lung cancer patients generally are smokers. The smoking habits of the rest of the cohort could not be evaluated with the same precision. However, according to the questionnaire data collected for present foundry workers (8), there is no reason to believe that the smoking habits of foundry workers essentially differ from those of the general male population. Thus the excess lung cancer mortality of the iron foundry workers can hardly be explained by smoking. A more likely explanation is that the foundry environment really contains carcinogenic agents, which perhaps require smoking as a cocarcinogen. We are now making efforts to identify those compounds.

\section{Coronary mortality}

The occupational factors that may cause excess coronary disease in foundry workers have been discussed in another context. The conclusion was that carbon monoxide was the most important (7).

Although the observed number of coronary deaths were rather high in some occupational and exposure categories, there was no clear indication that foundry work increases the risk of dying from coronary heart disease. The highest SMRs were observed for the molders and coremakers, on one hand, and for the carbon monoxide exposed category of casters and furnacemen, on the other. However no difference was significant. This result is interesting because angina showed a clear dose-response relationship with carbon monoxide exposure in active foundry workers (7).

When carbon monoxide exposure is considered a causative factor for coronary heart disease, the failure to find excess mortality among those exposed may be due to too small exposure differences between the "exposed" and the "unexposed," i.e., the general population or other categories of foundry workers. First all categories contain about the same proportion of smokers, and therefore the reference category is by no means "clean" with regard to carbon monoxide exposure. Second carbon monoxide exposure is intermittent in foundries and only part of the "exposed" actually have higher carboxyhemoglobin values than from smoking alone (17). Health selection may 
have also contributed to the negative finding; its possible impact has been discussed elsewhere (10). For these reasons this study must be regarded as rather noninformative with respect to a possible effect of carbon monoxide exposure upon coronary mortality. The ideal study would be restricted to nonsmokers with established carbon monoxide exposure and would require a prospective design.

\section{Violent deaths}

The total number of violent deaths did not differ from the expected figures in any occupational group. The healthy worker effect is negligible when violent deaths are concerned; thus the results were not confused by this effect. Closer analysis showed, however, that violent deaths were more frequent among the younger age groups, among those with a short duration of exposure, and among common laborers. These results can be explained better by social than by occupational factors. For example, it was exceptionally difficult to trace those exposed for less than 1 year. Furthermore, the response rate to the questionnaire was low in that group (10). Additional indications were a high frequency of suicide and the fact that alcohol was a contributing factor in every third violent death. The fact that such features were prominent among the foundry workers probably has little to do with the work itself. During economically favorable periods the criteria for the preemployment selection of workers are low, and turnover becomes great. However, temporary workers are by no means typical of foundries only; all other industries sensitive to economic fluctuations have the same problem. Hence the same type of results would probably have been obtained from all such industries.

\section{ACKNOWLEDGMENTS}

Ms. Raija Vuorela and Ms. Hilkka Tiainen collected the data from the employers' records and from the various registers used in this study. Ms. Eira Böhm assisted in the calculation of mortality data and in the elucidation of the working history of the lung cancer cases. Ms. Marja-Liisa Korkala drew the figures. We wish to express our sincerest thanks to them all.

\section{REFERENCES}

1. AHLMAN, K., BACKMAN, A.-L., HANNUNKARI, I., JÄRVINEN, E., KOPONEN, M., KOSKELA, R.-S., PARTANEN, T., SEPPÄLÄINEN, A. M. and STARCK, J. Kivityöntekijöiden työolosuhteet ja terveydentila. [Work conditions and health of granite workers] (Kansaneläkelaitoksen julkaisuja AL: 4/1975) The Social Insurance Institution, Helsinki 1975. 128 p. (English summary)

2. AHLMAN, K., BACKMAN, A.-L., KOSKELA, R.-S. and LUOMA, K. Satamatyöntekijöiden työolot ja terveydentila [The health and work conditions of dock workers] (Työterveyslaitoksen tutkimuksia no. 105). Institute of Occupational Health, Helsinki 1975. 64 p. (English summary)

3. CAVIGNEAUX, A. Action cancérogène des huiles minérales utilisées en métallurgie. Cah. notes Doc. 3 (1973) 315-319.

4. ENTERLINE, P. E. Mortality among asbestos product workers in the U.S. Ann. n.y. acad. sci 132 (1965) 156-165.

5. ENTERLINE, P. E. Comment to J. Goldsmith: "What do we expect from an occupational cohort?" J. occup. med. 17 (1975) $127-128$.

6. HERNBERG, S. The Finnish foundry project: Background and general methodology. Scand. j. work environ. \& health 2 (1976): suppl. 1, 8-12.

7. HERNBERG, S., KÄRÄVÄ, R., KOSKELA, R.-S. and LUOMA, K. Angina pectoris, ECG findings and blood pressure of foundry workers in relation to carbon monoxide exposure. Scand. j. work environ. \& health 2 (1976): suppl. 1, 54-63.

8. KÄRÄVÄ, R., HERNBERG, S., KOSKELA, R.-S. and LUOMA, K. Prevalence of pneumoconiosis and chronic bronchitis in foundry workers. Scand. $j$. work environ. \& health 2 (1976): suppl. 1, 64-72.

9. KITIGAWA, G. M. and HAUSER, P. M. Differential mortality in the United States. Harvard University Press 1973.

10. KOSKELA, R.-S., LUOMA, $K$. and HERNBERG, S. Turnover and health selection among foundry workers. Scand. j. work environ. \& health 2 (1976): suppl. 1, 90-105.

11. LLOYD, J. W. and CIOCCO, A. Longterm mortality study of steelworkers: I. Methodology. J. occup med. 11 (1969) 299 -310 .

12. MC LAUGHLIN, A. I. G. and HARDING, H. E. Pneumoconiosis and other causes of death in iron and steel foundry workers. Arch. ind. health 14 (1956) 300-378.

13. MC MICHAEL, A. J., SPIRTAS, R. and KUPPER, L. L. An epidemiologic study 
of mortality within a cohort of rubber workers 1964-72. J. occup. med. 16 (1974) $458-464$.

14. PARTANEN, T., ASP, S. and KOSKELA, R.-S. TVH:n tie- ja rakennusmestarien virkahistoria, työkyvyttömyys ja kuolleisuus [The occupational history, disability and mortality of road and building contractors working for the National Board of Roads and Waters] (Työterveyslaitoksen tutkimus). Institute of Occupational Health, Helsinki 1972. 10 p.

15. REDMOND, C. K., CIOCCO, A., LLOYD, J. W. and RUSH, H. W. Long-term mortality study of steelworkers: VI. Mortality from malignant neoplasms among coke oven workers. J. occup. med. 14 (1972) 621 -629 .
16. TANIMURA, H. Benzo(a) pyrene in an iron and steel works. Arch. environ. health 17 (1968) 172-177.

17. VIRTAMO, $M$. and TOSSAVAINEN, $A$. Carbon monoxide in foundry air. Scand. j. work environ. \& health 2 (1976): suppl. 1, $37-41$.

18. WORLD HEALTH ORGANIZATION. The international statistical classification of diseases, injuries and causes of death. Helsinki 1969. $234 \mathrm{p}$.

19. WORLD HEALTH ORGANIZATION. World health statistics annual 1967: Vital statistics and causes of death. Geneva 1970.

20. ZDRAZIL, J. and PICHA, F. Kancerogenni uhlovodiky — 3,4-benzpyren - v ovzduší. Slévárenství 13 (1965) 198-199. (English summary) 